\title{
Batlles reales y batlles de sachs. Contribución al estudio de las jurisdicciones locales catalanas en la Baja Edad Media y a las puertas de la Edad Moderna ${ }^{1}$
}

\author{
Maria Asunción Zapata Buxens
}

\section{RESUMEN}

Batlles reales $y$ batlles de sachs.

Contribución al estudio de las jurisdicciones locales catalanas en la Baja Edad Media y a las puertas de la

Edad Moderna.

A través del ejemplo de la baronia Desbosc, el estudio se ocupa de la resistencia de los habitantes de las

poblaciones catalanas contra la jurisdicción encarnada tanto por el batlle de sachs, el juez señorial, como por el batlle real, el juez del monarca, porque ambos magistrados representan a los ojos de los municipios la misma clase de justicia. Ésta es la prueba de la pervivencia de elementos feudales, fiscales y legales, heredados de la Edad Media en la sociedad catalana de los primeros tiempos modernos.

\section{ABSTRACT}

Batlles reales and batlles de sachs. $A$ contribution to the study of Catalan local jurisdictions at the end of the Middle Ages and at the dawn of the Modern Times.

Using the baronia Desbosc as an example, the study deals with the resistance of the inhabitants of the Catalan villages both against the jurisdiction embodied by the batlle de sachs, the lord's official, and that embodied by the batlle real, the royal official, because both magistrates are considered by the municipalities as representing the same kind of justice. This is the evidence of the survival of legal and fiscal feudal elements inherited from the Middle Ages in Catalan society in the Early modern times.

1 Este artículo es una versión abreviada del trabajo de investigación presentado en este Departamento de la UNED para la obtención de 9 créditos en el Programa de Tercer Ciclo. 


\section{JURISDICCIÓN INFERIOR Y BATLLIASS EN CATALUÑA}

La justicia local de la Baja Edad Media en Cataluña ha sido poco estudiada ${ }^{2}$, faltando como consecuencia una visión global y actualizada de la administración de justicia y de las instituciones para esta zona. En general, el derecho feudal catalán se sustentó sobre las bases de: el derecho consuetudinario, que persiste a pesar de la aparición de nuevas fuentes legales, el feudalismo inherente en todas las relaciones (las convenientae o pactos feudales siguen presidiendo el régimen jurídico de los feudos), la recepción del derecho romano, y por último las Constituciones reales que nacen del sistema político del pactismo, y se incorporan paulatinamente a la legislación. Se trata de un sistema legal incipiente con muchos vacíos que permiten actuaciones distintas según la zona, siendo la justicia administrada dentro del concepto de feudo, a nivel general por el monarca, señor de sus vasallos, y a nivel local a través de los señoríos.

Tras la Sentencia Arbitral de Guadalupe, parece ser que la legislación catalana se encaminó a una mayor defensa y endurecimiento del sistema feudal, mayormente respecto al control de las alienaciones y del pago de los censos ${ }^{3}$. De manera que, a finales de la Edad Media y principios de la Edad Moderna, el Derecho en Cataluña sigue manteniendo los aspectos medievales más reforzados y arraigados a través de las relaciones feudovasalláticas, presentes en todas las áreas de poder, principalmente en las del mundo rural. Los nuevos propietarios de los feudos aprovecharán la ambigüedad y la falta de definición del sistema en su propio beneficio. El barón adquiere con su propiedad una serie de derechos sobre el término: el destret o monopolio, además de los diezmos, censos, derechos de obras, cargas y multitud de servicios. El mismo sistema de explotación agrícola sigue basándose en el establecimiento enfitéutico que queda reflejado en las confesiones de los capbreus. Esta relación de dependencia tiene como objetivo la seguridad en la explotación de la tierra, a la vez que la obtención de beneficios rentistas.

La jurisdicción se halla parcelada entre las denominadas de mer y las de mixt imperi. Mer imperi era la jurisdicción que afectaba a los procedimientos que comportaban sentencia de pena de muerte, pérdida o mutilación de miembros, expoliación, etc. Y mixt imperi significaba la facultad

TurRull, M. La configuració jurídica del municipi baix medieval. Règim municipal i fiscalitat a Cervera 1182-1430. Barcelona, Fundació Noguera, 1990, p. 370.

3 Serra, E. Pagesos i senyors a la Catalunya del segle xvI. Barcelona, Crítica, 1988, p. 49 
para decidir en causas civiles, contenciosas, gubernativas y en las criminales que comportasen penas leves. La organización de la jurisdicción de la totalidad del territorio, competencia real, que estaría teóricamente por encima de las demás, era repartida en sucesivas jurisdicciones hasta llegar a la más reducida, la del castell termenat ${ }^{4}$.

El rey es el primer señor jurisdiccional de sus tierras y vasallos, y los barones sus oficiales, sobre los que traspasa las competencias de distinta índole. Además, con una nula distinción entre derecho público y privado, en una época en que la autoridad la tiene el monarca por juramento feudal de sus vasallos, fue posible la concepción de la jurisdicción como patrimonio. Este carácter patrimonial explica que las jurisdicciones puedan ser objeto de compra-venta, donación o permuta. De manera que el poder judicial y ejecutivo local está en manos de oficiales locales que lo ostentan para detener a los criminales, instruir diligencias de causas, exigir impuestos, emitir bandos, incautar bienes, ponerlos en pública subasta, etc.

Por lo que hace a la justicia local, podemos afirmar que en la Corona de Aragón existía una cierta confusión o indefinición ya que con respecto a ella actuaban: el rey (directamente), el consejo municipal, el veguer (responsable de la jurisdicción real) y finalmente el batlle (delegado del patrimonio del rey). En la actuación de estos dos últimos existen también interferencias, ya que en ocasiones el batlle ejerce el mixt imperi y el veguer el mer imperi. Los representantes municipales, al margen de los funcionarios reales, tienen también competencias penales y participan en gran número de tareas pacificadoras y arbitrales. A su vez, el rey dispone de sus propios funcionarios que reciben el mismo nombre que los oficiales señoriales (batlles), con similar funcionamiento, competiéndoles la jurisdicción local en las zonas donde no existe el señorío.

A todo ello hay que añadir que el señorío, durante la Edad Media e iniciada la Edad Moderna en Cataluña, se convierte en el conjunto que define el hábitat rural. De manera que durante el siglo XVI, no sólo no disminuye, sino que aumenta su presencia (entre el $75 \%$ y el $80 \%$ del territorio se halla bajo la jurisdicción señorial) ${ }^{5}$, así como el mismo poder señorial. Se trata de una coyuntura semejante a la del resto de Europa y que de forma paralela irá en franco incremento. Simultáneamente, se detecta un proceso de fragmentación de las jurisdicciones y como sea que, aunque

\footnotetext{
4 PONS I GuRI, J.M. "Compendi sobre els drets dels castells termenats", en: Recull d'estudis d'Història jurídica catalana. Vol. III. Barcelona, Fundació Noguera, 1989, pp. 341-352.

5 SaLES, N. “Els segles de la decadència, ss. XVI-XVII», en: Història de Catalunya, Vol. IV. Barcelona, 62, 1989, p. 155.
} 
sólo en la teoría, las ordenanzas señoriales no pueden contradecir el derecho real, nos hallamos ante una difícil delimitación de los señoríos jurisdiccionales y reales.

La llegada del Estado Moderno no hace desaparecer la jurisdicción feudal, que sigue constituyendo una de las bases del poder de la nobleza. Por encima de la propiedad o dominio directo de la tierra, están los amplios poderes de gobierno y jurisdicción otorgados por el monarca. Se trata, en definitiva, de un evidente traspaso de competencias públicas de la Corona a los señores altamente rentabilizadas. Además, la administración de los señorios, caótica e inconcreta, pretendia en muchas ocasiones, cobrar rentas e impuestos de dudosa procedencia, establecer monopolios y apropiarse de bienes que no le pertenecían. $Y$, como consecuencia natural, también eran generalizados los abusos de los oficiales que con frecuencia aprovechaban sus cargos para obtener beneficios personales.

Por lo que hace a esos oficiales señoriales, los batlles, así como desde el siglo x la administración de los castillos se había confiado a la pequeña nobleza con el título de castlans, durante la Baja Edad Media se darán las propiedades a barones que a su vez nombrarán funcionarios para que las administren: capitanes de castillos (castlans) y batlles. El batlle es por tanto el oficial que se ocupa del gobierno y la administración en el ámbito local, siendo la batllía a su vez un distrito jurisdiccional especial, gobernado por un bailus delegado del rey o señor en la vila. Por lo que se refiere al ejercicio de la justícia, el batlle del siglo XIV asume la jurisdicción ordinaria heredada de la anterior curia o cort ${ }^{6}$, competiéndole las causas civiles y criminales. Con el paso del tiempo fue adquiriendo otras funciones judiciales, convirtiéndose finalmente en una verdadera autoridad que actuaba como magistrado público.

El nombramiento de los batlles sufre una importante evolución a lo largo de la Edad Media, ya que, si en un principio el cargo es hereditario y concedido por el señor, posteriormente será elegido por el Consejo de la Universidad de entre los hombres del término y por un periodo de tres años. Como vemos, se pasa de un oficial feudal (batlle del noble) a lo que podríamos considerar un cargo representativo dentro del gobierno local (batlle local o natural). Cuando se trata de un batlle feudal el nombramiento se hace como establecimiento y es un cargo sin límite temporal que en ocasiones puede ser hereditario. El batlle real en cambio suele coincidir con la elección entre una terna presentada y una duración tria-

LALINDE Abadía, J. La jurisdicción real inferior. Barcelona, Seminario de Arqueología e Historia de la ciudad, 1966, pp. 57-257 
nual. A pesar de esta evolución, durante la época que estudiamos, se siguen nombrando batlles señoriales y naturales simultáneamente, tanto por parte del señor feudal, como del Consejo del muncipio respectivamente.

Disponemos de pocos datos para teorizar sobre la retribución del batlle. Sin embargo hemos comprobado que cuando ejerce el cargo como establecimiento enfitéutico recibe las partes que constan en el contrato feudal que pueden ser tanto monetarias como en especies, por ello en algunos estudios aparece percibiendo el redelme o la tercera parte del diezmo. Es normal que como oficiales que cobran las rentas, perciban parte de ellas. Tenemos también la constatación de su prestigio económico y social: "si vivien noblement, menjaven pa de blat i tenien un cavall..." (Usatges de Barcelona).

En cualquier caso, y a pesar de las generalizaciones que hemos avanzado, al revisar la bibliografía existente encontramos un gran vacío respecto al cargo de batlle de sachs, el principal oficial señorial. Los estudios sobre estos temas de jurisdicción, principalmente de la mano de Pons i Guri ${ }^{7}$ y Font i Rius ${ }^{8}$, nos definen el batlle como una pieza más de la jurisdicción inferior, en un entorno conflictivo y que pervive en los inicios de la Edad Moderna. Otros autores mencionan la existencia de conflictos jurisdiccionales, pero en ningún estudio local ni general se habla del conflicto por solapamiento de competencias entre el batlle real y el señorial que nosotros advertimos en nuestra investigación, ni se dice que en algún momento actúen conjuntamente.

\section{LA BATLLÍA EN LA BARONÍA DESBOSC}

La baronía Desbosc, es decir el dominio conjunto del castillo de Sant Vicenç o Burriac y del de Vilassar, abarca el territorio de los actuales municipios de Argentona, Vilassar de Mar, Vilassar de Dalt, Premià y Cabrera de la comarca del Maresme. Esta baronía se hallaba durante la Edad Media limitada por el señorío feudal de Cabrera al norte, y al sur por el dominio de la ciudad de Mataró, que pronto pasó a gozar del privilegio de universidad independiente. También hemos de tener en cuenta, al hablar de la ubicación de esta baronía, su relativa proximidad con Barcelona.

\footnotetext{
7 PONS i GuRı, J.M. “Jurisdiccions compartides a la Catalunya Baix-Medieval», en Recull d'estudis d'Història jurídica catalana. Vol. III. Barcelona, Fundació Noguera, 1989, pp. 119-126.

8 FONT i Rius, J. M. "Orígenes del régimen municipal de Cataluña", en Estudis sobre els drets $i$ institucions locals a la Catalunya Medieval. Barcelona, Universitat de Barcelona, 1985, pp. 281-305.
} 
Esta proximidad hacía que las distintas poblaciones reclamasen el derecho de ser nombradas carrer de Barcelona, con la pretensión de disfrutar de la jurisdicción real.

Como ya hemos dicho, en este momento es posible comprar las propiedades con pleno derecho de jurisdicción sobre ellas, manteniéndose el concepto patrimonial de la jurisdicción. Cuando Berengueró, señor de Sant Vicenç, muere en 1348 a causa de la peste negra, tiene lugar la subasta de sus castillos, las tierras de la casa de Cabrera y el beneficio de la capilla del castillo de Sant Vicenç. Pere Desbosc el viejo, escriba del rey, adquiere estos bienes. En esta compra se incluyen además del castillo de San Vicenç (conocido también con el nombre de Burriac), el castillo de Vilassar y la torre del Cogoll, y otras propiedades como torres, mansus, bordas, cabañas, hombres y mujeres, censos, servicios, derechos, usos, tierras, aguas, fuentes e industrias (herrerias y molinos) ${ }^{9}$. Es curioso como estos ciudadanos ricos venidos del medio urbano, al adquirir propiedades rurales, manifiestan con sus exigencias una tendencia a acrecentar la dureza del feudalismo, es decir a hacer valer sus derechos como feudales. Efectivamente, los mecanismos señoriales les permitirían el acceso a las rentas de sus nuevas propiedades. Con toda la propiedad adquirian también la jurisdicción de la misma, que puede decirse se materializaba con el permiso real de construcción del "costell" (picota), derecho contra el cual litigaron los campesinos del lugar.

Los favores que Pere Desbosc había dispensado al monarca durante la guerra con Castilla le dieron finalmente no sólo la propiedad sino también toda la jurisdicción ("mer imperi i tota jurisdicció") del término. A todo ello los habitantes de dichas poblaciones no permanecerian impasibles; siguiendo la tónica general durante el siglo $\mathrm{xv}$, los consejos de las universidades iniciaron un proceso de recuperación de sus derechos en contra de los feudales, y dentro de esta misma coyuntura histórica situamos la trayectoria de Vilassar, Argentona y Cabrera, las poblaciones que permanecían bajo la jurisdicción de la llamada baronía de Sant Vicenç. En 1419 interviene el Batlle General de Cataluña para reintegrar a la Corona la jurisdicción que retiene Desbosc, el rey evalúa en 10.000 sueldos los servicios prestados por los Desbosc y pide el pago de esta suma a los habitantes de estos municipios para liberarles de la jurisdicción del feudal.

Será uno de los sucesores de la familia Desbosc, Miquel Desbosc y de Sant Vicenç (1552-1573), quien al recibir en 1563 el título de noble re-

\footnotetext{
9 Cuadrada C.; Busqueta. "Un grup social a la conquesia de l'entorn rural", en L'Avenç, $n$.
} 93, mayo 1986 , pp. $36-39$. 
clamará las jurisdicciones civiles y criminales de Vilassar, Cabrera y Argentona, invocando derechos antiguos. Así se abrirá un largo pleito, que parece ser que aún continúa cuando Frederic Desbosc y de Sant Vicenç (1575-1589) recibe una resolución en 1588 por la que se le priva de que su batlle de sachs pueda proceder ejecutivamente contra sus deudores.

Precisamente, el cuerpo documental, principal objeto de nuestra investigación, es la copia de los manuscritos que fueron utilizados en 1567 para el pleito por la jurisdicción civil y criminal, entre el noble Miquel Desbosc y los síndicos de las universidades de los municipios afectados ${ }^{10}$. Se trata de más de dos mil páginas manuscritas, cosidas posteriormente a su utilización sin un orden aparente. Contienen básicamente: Declaraciones juradas, interrogatorios, copias de confesiones, demandas de documentación, y los llamados Llibres de Cort que constituyen el apartado más interesante, ya que se trata de las copias de los libros del batlle de sachs, en los que quedan reflejados todos los actos que emanan de la jurisdicción señorial.

En estas copias de los Llibres de Cort encontramos el nombre de los batlles, los años que ejercieron su mandato y los actos ejecutivos que llevaron a cabo. De estos batlles, algunos son nombrados por el señor y otros aparecen como batlles reales. Los dos primeros de los que tenemos referencia son Martí Morell establecido en la batllía de Vilassar por Pere de Sant Vicenç (posiblemente entre 1162 y 1188), y Ramon establecido en la batllía de Argentona por Berenguer de Sant Vicenç (en 1232). Según la documentación, en estos dos casos la batllía se concedió como un establecimiento, al que se añade la posesión de un feudo. Desde un principio podemos apreciar como el batlle de sachs es el batlle señorial cuya función consiste en administrar las rentas de un señor territorial, recaudar los réditos de los enfiteutas y arrendatarios, y reclamar los servicios personales y los mals usos. Recibe las cabreaciones, los homenajes, etc., y levanta acta de todos los actos ejecutivos. Es, en definitiva, el cargo ejecutivo de la jurisdicción dominical.

Uno de los primeros batlles señoriales de los que encontramos información más completa es Bernat de Flor ${ }^{11}$, batlle de sachs nombrado por Pere Desbosc (1352). En su confesión declara como Bernat de Flor del mas Marqués de la parroquia y término de Vilassar, y confiesa por la batlía del castillo en perpetuidad para ejercer justicia, recoger los censos y

\footnotetext{
10 Dicha documentación se encuentra en el Archivo Histórico Municipal de Argentona.

"En la documentación complementaria hallamos más información sobre este batlle. Destaca una relación de confesiones de los hombres de Vilassar en las que dicen que pagan sus censos al batlle Bernat de Flor que lo es por el noble Pere Desbosc.
} 
las partes de los agricultores. En el contrato se especifica la cantidad de trigo a percibir, una vez hechas las partes, después de recogida la cosecha con el trigo maduro, y los pagos en metálico que deben hacerle los vecinos en virtud de su batllia.

A través de las declaraciones presentadas como prueba, hallamos también la historia de una familia que ostentó de forma hereditaria el cargo de batlle de sachs. Se trata de la familia Julià, que aparece en las declaraciones tomadas durante el verano de 1567. Por el contenido de las mismas hemos de situarla como contemporánea a la causa. Así, los Julià ejercen el cargo de batlle en Argentona, Vilassar y Cabrera como oficiales del noble don Miquel Desbosc, según afirman diversos testigos.

En primer lugar Bertomeu Lauder, herrero de Argentona, declara que hace aproximadamente veintidós años que ha visto al padre del actual batlle Amador Julià que recogía los diezmos y rentas de los campesinos de Argentona, Vilassar y Cabrera, como e batlle de sachs nombrado por don Miquel Desbosc. También dice en su declaración que cuando alguien no quería pagar los diezmos y censos, el batlle de sachs "per que no se mogués escàndol" pedía ayuda al batlle del lugar. Del mismo modo el oficial señorial también utilizaba el mensajero del lugar. Así,había pedido la colaboración al de Mataró para actuar contra los habitantes de esta ciutat que le debían censos.

Joan Julià de Vilassar, declara que él, y su padre mientras vivía, recogían los censos de los de Vilassar, aunque nunca había visto ni oído que lo hiciesen como batlles de sachs. Pero sí recuerda que el mensajero y el portero real actuaban en ocasiones bajo las órdenes de don Miquel Desbosc.

Esteve Tolrà, payés de Vilassar del vecindario de Cabrils (parroquia de Vilassar) declara que ha oído decir que los predecesores de don Miquel Desbosc habían establecido allí una batlía, y que ésta había cobrado muchas partes y braçatges desde hacía unos 25 años. También que un tal Miquel Riera payés de Vilassar cobraba dichas partes y braçatges al dicho noble, aurque no sabía que lo hiciese como batlle de sachs. Del mismo modo recordaba que la familia Julià recogía las rentas de los campesinos del lugar.

Un último testigo, Amador Julià de Sant Genís de Vilassar, testificó que su padre fue nombrado batlle de sachs por Miquel Desbosc para cobrar partes, censos y diezmos a los de Argentona, Cabrera y Vilassar. Y que después de morir su padre, los recogía él por don Francesc Desbosc, hijo de don Miquel, por lo que le había prestado sacramento y homenaje. Así mismo afirma que es verdad y justo que Miquel Desbosc cuente con la ayuda de un oficial real que asista al batlle de sachs. Del mismo modo, se 
presentó como prueba también el nombramiento de Amador Julià, hecho en 1558 por muerte de su hermano Antoni Julià. En él Miquel Desbosc nombraba al dicho Antoni Julià para que cobrase los censos en los términos de Vilassar, Argentona y Cabrera.

De esta serie de declaraciones y pruebas puede deducirse que el noble don Miquel Desbosc y sus antecesores, para cobrar los censos enfitéuticos, disponían de una batlía propia, y que a la cabeza de ésta estaba el batlle de sachs, nombrado por el señor feudal como oficial suyo. Además, vemos que efectivamente se trataba de un cargo hereditario. En ocasiones, los campesinos declarantes no saben muy bien si existían oficiales nombrados por el señor, ni el nombre exacto de su cargo; aunque sí recuerdan que eran los que cobraban los censos. También dejan constancia de que para evitar violencias, cuando algún enfiteuta se resistía, era pedida la asistencia al batlle y al portero real. Sin embargo, en algunos casos dicha asistencia por parte del oficial real tampoco era suficiente para impedir los incidentes.

En definitiva, la documentación presentada por la parte noble para el proceso que estudiamos, nos muestra el empeño del señor feudal por demostrar que desde siempre ha ejercido su poder fiscal y judicial mediante su oficial, el batlle de sachs, y que éste en ocasiones incluso ha contado con la colaboración de los agentes reales. Los síndicos del Consejo tratan de demostrar, por contra, que quienes están ejerciendo desde siempre el poder ejecutivo han sido los batlles reales, y que el señor nunca ha ostentado la jurisdicción del lugar. Así el cargo de batlle se convierte en este pleito en la piedra angular, la prueba irrefutable que habría de demostrar a quién pertenecía la jurisdicción.

Siguiendo con el contenido de los libros de corte, hallamos como batlles en Vilassar a Salvador Abril (1524), Bernat Teià (1533) y Bertomeu Amat (1545), que en el título de su libro constan como señoriales. A continuación, por orden cronológico, Jaume Parera (1515), de nuevo Salvador Abril (1526), Benet Teià (1533), Joan Bernat (1542), Amador Parera (1551), Bernat Aroles (1560) y Bernat Casals (1567) son los nombrados por reial mà. A pesar de coincidir los nombres en algún caso, el notario los recoge por separado y, tal como debieron ser los originales, bajo distinta titulación como agente señorial y como agente real. Por tanto hemos de deducir que actuaron indistintamente bajo mandato real y señorial.

Para Argentona no hallamos copiado ninguno con la titulación de señorial. Son, por orden cronológico: Guillem Pere Bellot (1480), Joan Bellot (1521), Bertomeu Parera (1539), Rafael Pujol (1551), Joan Castell (1554) y Jaume Mateu (1563). En cualquier caso, según consta en las ejecucio- 
nes, el batlle real y el señorial actuaban indistintamente a favor de los derechos feudales del señor por medio de amparas e incautaciones. Dado su poder ejecutivo, los batlles de sachs también se encargaban de castigar a los delincuentes (en un documento el honorable Rafael Pujol, batlle real de la parroquia de Argentona, procede contra personas y bienes por delitos). Procedimientos que el noble quiere ver declarados como legítimos suyos por los derechos fiscales que dice poseer.

Hemos podido comprobar también que los síndicos nunca cuestionan el derecho al cobro de impuestos o rentas por parte del señor feudal; sólo niegan que tenga derecho a cobrarlos mediante un oficial suyo y por tanto que posea la jurisdicción señorial. Pero para el señor es evidente que, si tiene derecho a cobrar rentas, ha de poder proceder ejecutivamente contra sus deudores. En el estudio que hace Max Turull del privilegio concedido a Cervera por Jaume II en 1320, afirma que el único que puede imponer penes i bans y a quien correspondía pregonarlo era al batlle real, y analiza este hecho como un derecho que adquiere el batlle, «guardando la paternidad de la acción» 12 .

Efectivamente, siguiendo el hilo conductor de nuestra exposición, recordemos que la acción real desde un principio es subsidiaria en las zonas donde no existe señorío. Por tanto, es lógico que el señor feudal, que ha recibido la jurisdicción de manos reales, se crea con derecho, y tal reclame, de ejecutarla mediante sus propios agentes e incluso con la colaboración de los agentes reales. En esta causa por las jurisdicciones, si bien los libros de corte fueron presentados para demostrar el poder ejecutivo del noble, en ellos hallamos cómo se lleva a cabo el poder ejecutivo del batlle, tanto real como señorial.

\section{PROCESOS EJECUTIVOS}

El poder ejecutivo que ostentaron los oficiales de la baronía Desbosc se concreta básicamente en tres acciones: bans, ampares y empenyoraments. Dichas acciones quedan reflejadas en las actas de los llibres de cort presentados como prueba en el proceso ${ }^{13}$.

Los bans son disposiciones en las que, a instancia de un demandante, el agente (real o señorial) decreta protección sobre determinadas propie-

TURuLl, M. La configuració..., pp. 370-409.

Hemos podido analizar el contenido de siete libros de cort para Argentona y seis para $\mathrm{Vi}$ lassar en un periodo comprendido entre 1480 y 1566, obteniendo como resultado una base de datos más amplia, válida para futuras investigaciones en la zona. 
dades mediante la amenaza de multa. Según Turull ${ }^{14}$ el ban es el castigo o multa por haber contravenido la orden dada, que generalmente se expresa en valor monetario, que oscila dentro de unas cantidades límite (entre 2 y 100 sueldos), siendo la pena en metálico proporcional a la infracción. La parte proporcional que se queda el batlle o paer varía, hasta que a finales del siglo XIV lo hallamos fijado en: un tercio para el batlle, un tercio el Consejo y un tercio para el delator.

En el análisis que hacemos de la documentación estudiada, llegamos a la conclusión de que, a pesar de hallarse comprendidos entre inicios y mediados del siglo xvi, los bans de los libros de la baronía Desbosc responden a la mayoría de aseveraciones que hace Turull i Rubinat, aunque hayamos de añadir algunos aspectos: En primer lugar, el proceso que el autor atribuye al batlle real, es utilizado del mismo modo por el batlle del señor feudal y consta en los libros de su corte. $Y$ en segundo lugar, la cantidad de la multa es doble si se comete el delito de noche ( $V \mathrm{~V}$ de die et $X$ de nocte"). Se recogen en los libros de cort 193 ejecuciones de este tipo. El demandante del ban es normalmente el propietario de las tierras que pide que se protejan y los motivos son casi siempre que no pasen rebaños por sus sembrados, que no le roben las uvas de su propiedad, que no se interrumpan las aguas de los riegos... En algunas ocasiones el demandante del ban es el Consejo de Vilassar, nombrado como jurats $i$ consell, y en otras el mismo señor feudal. Es decir que, si nos guiamos por estas pruebas, podemos deducir que el señor feudal y el Consejo municipal, que en el pleito se hallan en pugna por el control del poder jurisidiccional, habían recurrido a este procedimiento ejecutivo, y conminando al mismo batlle para su ejecución ${ }^{15}$.

Con el procedimiento de ampara se señalaba ${ }^{16}$ la propiedad amparada, es decir hipotecada. La hipoteca se lleva a cabo siempre por deudas de censos, y recaía sobre productos de cultivo: trigo, cebada, y sembrados en general, y otros como cal, leña...

Y por último, el empenyorament consistía en sustraer un objeto a modo de prenda de manera que el deudor no pudiese recuperarlo hasta que pagara la deuda. Es decir se trata del mismo caso que el de las amparas, pero con bienes muebles menores. Todas las incautaciones analizadas están promovidas por la demanda de los censos impagados a los nobles.

\footnotetext{
14 Turull, M. La configuració..., pp. 382-384.

15 El mismo síndico Bernat Aroles, que lleva la causa contra el noble, había actuado anteriormente como batlle, presidiendo un ban por el Consell de Vilassar y otro por Miquel Desbosc.

16 La señal suele ser una cruz de caña.
} 
Es éste uno de los apartados más curiosos, ya que nos ofrece una larga lista de objetos expropiados dentro de lo que adivinamos un proceso largo y no siempre efectivo. Estudiando los empenyoraments de la documentación, podemos observar que existe una gran cantidad de incautaciones, es decir de impagados. Además, los objetos retenidos (azadas, cofres, botas, mantas, rastrillos, ollas e incluso un cerdo y una mula) demuestran la pobreza de las gentes implicadas y que siempre estos actos recaían sobre la población campesina.

\section{ACTUACIÓN CONJUNTA DE LOS OFICIALES}

Uno de los aspectos inéditos que puede aportar nuestra investigación es la actuación conjunta de los oficiales reales y señoriales. Mientras que en la bibliografía consultada se definen y distinguen según se hallen bajo jurisdicción real o señorial, jamás los encontramos actuando conjuntamente. Sin embargo, en el proceso que examinamos, es el señor feudal el que presenta, como prueba de su derecho a la jurisdicción y a tener oficiales propios para ejecutarla, el hecho de que en muchas ocasiones han actuado conjuntamente ambos batlles. Así mismo, en los testimonios que hemos estudiado aparece constantemente la referencia de la asistencia de los oficiales reales al batlle de sachs con tal de prevenir violencias a la hora de cobrar los censos, cuando los deudores podían oponer resistencia.

En ocasiones el batlle real se niega a esta colaboración. Estas negativas son presentadas también como prueba por parte de los síndicos, como por ejemplo la del batlle real de Vilassar Bernat Casals, que había sido requerido por Bernat Borda mensajero de Francesc Desbosc. En ella vemos como la parte noble le recuerda que los libros de corte están llenos de casos en los que los batlles han hecho este tipo de servicios, el batlle real le responde que se maravilla de que le hagan estas demandas y pide que no se le vuelva a molestar en este sentido. Naturalmente, la asistencia del oficial real al señorial presupondría una aquiescencia del derecho del señor de usar su oficial o batlle y un precedente de legalidad. Por ello este aspecto se convierte también en eje de controversia por parte de unos y otros.

El noble defiende que, debido a la jurisdicción real que existe en aquella zona y a su necesidad y derecho a cobrar los censos sin provocar altercados, es lógico que se le dé asistencia por parte del oficial real. Vemos que no necesita cuestionar la jurisdicción real, ya que según él ésta no contradice la suya. Para demostrar que dicha asistencia sí se 
llevó a cabo, el noble aporta gran número de procesos completos. A su vez, los síndicos de Vilassar, dirigidos por Bernat Aroles reclaman el cumplimiento de la sentencia de 5 de marzo de 1456, según la cual el noble Miquel Desbosc no tiene jurisdicción alguna y no puede demostrar que haya obtenido asistencia del batlle real. Pero estas mismas protestas demuestran la existencia contemporánea de ambos oficiales: unos por parte real al servicio de la universidad, y otros por parte señorial, ejerciendo antiguos derechos feudales.

Durante la Edad Moderna, la jurisdicción señorial se ostenta por cesión real a cambio de dinero o servicios; por tanto, si el rey la da, la puede quitar también. De manera que las parcelas de jurisdicción real y baronial en general no se hallan definidas, provocando como consecuencia inevitable infinidad de problemas. Además el Consejo Municipal tenia plena facultad para dictar penes y bans, y el encargado de pregonarlo y de recaudar su importe era el batlle real, mientras que en las localidades de señorío seguía actuando el batlle señorial. Con ello tenemos ya suficiente motivo para que surgieran con frecuencia disensiones y conflictos entre la autoridad señorial y la comunidad de vecinos ${ }^{17}$.

Los síndicos de Vilassar argumentan que es el batlle local de la parroquia quien ejerce toda la jurisdicción por el rey, y que nunca ni don Miquel Desbosc ni sus predecesores han ostentado ningún tipo de jurisdicción, ni han ejecutado bajo derecho señorial alguno. Por tanto el batlle local, que depende de la jurisdicción real, debe recoger los censos y diezmos, mientras que el noble no tiene ningún derecho ni fiscal ni judicial sobre los términos. El señor feudal, a su vez, se define como señor de alodios, castillos y términos de Vilassar y de Argentona, situados dentro de la vegueria de Barcelona, y cita las Constitucions, Usatges i Commemoracions de Pere Albert, como base de sus derechos dominicales.

Es innegable que una situación de este tipo, en la que el señor feudal recibe la jurisdicción de una zona de manos del rey, quien a su vez la ostenta de forma subsidiaria, puede causar conflictos. $Y$ evidentemente, no sólo surgieron, sino que llenarían de contenido la lucha del poder municipal en contra del poder señorial. Conflictos que nacen a causa de las respectivas competencias de jurisdicciones ${ }^{18}$, y que originarán gran cantidad de pleitos que hallamos también en otros estudios locales de esta época.

TuRull, M. La configuració..., pp. 385-403.

18 Pons i GuRI, J.M. "Ordinacions procesals del vescomptat de Cabrera", en Reculls d'Història juridica catalana. Barcelona, Fundació Noguera, 1989. 


\section{LA MONARQUIA}

Para entender mejor las bases sobre las cuales se apoyaba la institución real en Cataluña, en primer lugar hemos de tener en cuenta su origen feudal, que hallamos en el mismo juramento que debian prestar los condes de Barcelona. Y, si a continuación analizamos la evolución desde su plenitud con Pere el Cerimoniòs hasta la guerra civil, nos encontramos ante un retroceso de la autoridad real propiciado por la politica denominada pactista, y que sitúa al rey a merced de los donativos de sus súbditos, con los que se ve obligado a negociar.

Nos consta la preocupación del mismo Pere el Cerimoniòs por dominar a la nobleza, preocupación que le llevó a intentar substituir el régimen tradicional de los castillos por "la costum d'Espanya». Uno de sus juristas Ramón de Abadal admitía que el derecho castellano permitía al rey ser el jefe directo de todos sus hombres, mientras que el «costum català » daba más poder a los castlans, es decir al estamento noble poseedor de feudos. Esta aristocracia no se enfrenta nunca abiertamente con la monarquía, ya que el rey siempre acaba cediendo para conseguir un compromiso ${ }^{19}$. $\mathrm{Fi}$ nalmente la ascensión de los Trastámara, que supuso la entronización de un rey extranjero gracias a la aceptación de la oligarquía catalana, terminan de debilitar la autoridad de la monarquía.

En efecto, el sistema político pactista, impuesto por el funcionamiento de las cortes, constituye un importante freno a las actuaciones del monarca y un límite de su autoridad. Esta autoridad condicionada, se traduce en una serie de disposiciones por parte del rey que en ocasiones favorecen a los sindicatos remensas, llegando incluso a permitir la convocatoria de los sacramentales en contra de los nobles, mientras que en otras se ponen del lado de la nobleza confirmando sus privilegios. La monarquía en este momento también juega un papel importante en la ascensión del patriciado urbano a clase dirigente y en la elevación de los ciutadans honrats a la categoría de caballeros ${ }^{20}$.

En Cataluña la monarquía absoluta no llegó a existir, lo que dio como consecuencia una administración descentralizada, vertebrada por la fidelidad privada, que en la Baja Edad Media se organizó como monarquía corporativa territorial dentro del marco jurídico y político de la Corona de Aragón ${ }^{21}$.

19 Salrach, J. M. Historia de Catalunya, dirigida per Pierre Vilar, Vol. Ill. Barcelona, 62, 1990 , p. 218 .

20 Solé, M. “Conversa amb. Torres Ribé». L' Avenç, febrero 1985, pp. 74-78.

21 Montagut, T. "Les institucions de govern", en Historia: Politica, Social i Cultural dels Països Catalans, Vol. III. Barcelona, Enciclopèdia Catalana, 1995, p. 294. 
Batlles reales $y$ batlles de sachs. Contribución al estudio de las jurisdicciones...

La Edad Moderna vive continuos intentos por parte del rey de imponer su autoridad. Un ejemplo de ello es la política de Fernando II que expresa la voluntad de ser cabeza, defensa y protección por la gracia divina del Principado de Cataluña, proponiéndose gobernar por "vice et manu regia" (decisión absoluta real) ${ }^{22}$. Por otra parte, el rey era la imagen de la justicia absoluta y la protección de todos sus vasallos. Para los campesinos y el pueblo llano en general representaba la justicia social y a quién reclamar ante los abusos señoriales. Evidentemente los monarcas jugaron esta baza y la de la ambición de la nobleza, en un contexto de vacío legal que llenaron con pragmáticas y concesiones.

Según nos muestran las Costums recogidas por Pere Albert, al rey pertenece la jurisdicción señorial, y la distinción entre el mer y el mixt imperi supone el dejar el primero en manos del reales, mientras las otras jurisdicciones pueden delegarse o venderse ${ }^{23}$, pero siempre estas cesiones se hacen por necesidad de subsidio ${ }^{24}$, así como para premiar fidelidades 0 servicios. Del mismo modo es indiscutible el carácter patrimonial de la jurisdicción real, ya que el rey no la posee como rey sino como señor jurisdiccional de todos sus vasallos ${ }^{25}$. Así, el régimen señorial, aparecido como sistema intermedio de administración a través de privilegios concretos, llega a asumir funciones públicas de fiscalidad y de justicia por cesión real ${ }^{26}$.

En el caso del conflicto remensa observamos como las pragmáticas reales a favor de la liberación de los mals usos dependen siempre de los donativos monetarios que solicite la Corona y de la dureza de la contestación noble ${ }^{27}$. Entre 1455 y 1460 , cuando el rey suspende momentáneamente la percepción del donativo, la nobleza reafirma sus inquietudes hacia los privilegios que puede perder. El vehículo de las reivindicaciones nobles es el Parlament, con la Generalitat a la cabeza. Mientras, la Generalitat, que sabe que si la causa común del rey y los remensas se lleva a cabo perderá toda fuerza, presenta en 1462 un proyecto de "concordia agraria". La maniobra es descubierta y el largo periodo (de 1462 a 1472) de Guerra Civil abre un inevitable paréntesis del que la autoridad monárquica sale reforzada. Sin embargo sigue condicionada a sus necesidades monetarias y a la continuación de la política parlamentaria del pactismo.

\footnotetext{
VICENS VIVES, J. Els Trastàmares. Barcelona, Vicens Vives, 1990, p. 216.

MONTAGUT, T. "Les institucions de govern...", p. 297.

MONTAGUT, T. "Les institucions de govern...", p. 306.

25 Ferro, V. El dret públic català. Les institucions fins el decret de Nova Planta. Vic, Eumo,

Lalinde Abadia, J. Derecho histórico español. Barcelona, Ariel, 1974, p. 242.

VILAR, P. Catalunya dins l'Espanya Moderna. Vol. II. Barcelona, 62, 1964, p. 199
}

1987, p. 106. 
En una de las disposiciones de las Cortes de 1480/81, el rey autoriza a percibir todos los derechos señoriales sobre los campesinos, por tanto los señores lanzan a sus agentes al cobro de viejas cargas. El motivo era que el rey necesitaba a cambio el apoyo de la nobleza y 300.000 libras. El 24 de agosto de 1483 se autorizan las reuniones de los remensas y la recaudación de los talls para el pago del donativo al monarca que les redimirá de los derechos señoriales. Finalmente el 21 de abril de 1486 se firma la Sentencia Arbitral de Guadalupe que elimina los mals usos, pero no la validez de la renta señorial. Tras esta Sentencia Arbitral, los campesinos obtienen la libertad personal y se aseguran la explotación a perpetuidad, mientras que el señor conserva la propiedad eminente y el control de las relaciones jurídicas feudales ${ }^{28}$.

Todo ello nos lleva a ver al monarca, por un lado como el artífice de la legalidad a través de las pragmáticas reales, pero por otro sujeto a las presiones de los distintos estamentos y de las necesidades económicas que origina su política expansionista. En el caso del proceso que hemos estudiado, la monarquía juega este doble papel, propiciando la confusión; de manera que los documentos producidos por mano real son utilizados tanto por la parte noble como por los síndicos de las universidades:

Los Desbosc presentan el documento en el que el rey Pedro de Aragón (1354) les concede la facultad para erigir picota y proceder contra los delincuentes, lo que presupone poseer toda la jurisdicción civil y criminal.

Los síndicos aportan la sentencia de la reina María (1419) en la que, como lugarteniente de Alfonso el Magnánimo, y ante la petición de Miquel Desbosc, resuelve que los oficiales señoriales no deben intervenir en los casos de jurisdicción civil, que son competencia de la veguería de Barcelona.

Por orden cronológico, sigue la sentencia dada por el rey don Juan de Navarra (1456), lugarteniente del rey Alfonso, en favor de los hombres de Vilassar y Argentona contra Joan Desbosc. Tras el examen de distintos documentos, resuelve que el noble no posee ninguna clase de jurisdicción en estos términos y que la jurisdicción compete al batlle real.

Otro documento, dado por el mismo rey Juan de Navarra en 1460, emite sentencia a favor de la familia Desbosc, anula la anterior favorable a las universidades y devuelve la jurisdicción al noble. Inmediatamente esta última sentencia es calificada por los síndicos de "sospitosa de fals", ya que, según ellos, ni tan sólo se halla en los registros; añaden además

23 Gaficia Carcel, R. Historia de Cataluña, ss. xvi-xvil, vol 1. Barcelona, Ariel, 1985, p. 224. 
otras muchas pruebas que nos demuestran su interés por declarar no válido el contenido de la misma.

Respecto al tema de las asistencias que deben realizar los oficiales reales a los batlles señoriales, y, que según los síndicos no son posibles, ya que el señor no tiene el dominio de la jurisdicción, Felipe II en uno de los documentos presentados apoya el hecho de que son lícitas, y en otro podemos leer la solicitud de presentación de los libros de corte de los batlles de sach de la baronía desde 1460, para probar la existencia de dichas asistencias.

La monarquía, en definitiva, dueña teórica de las jurisdicciones, las utiliza para venderlas a cambio de dinero o de favores y adquirirlas amparada en la legalidad. El feudal «invierte" comprando de nuevo las jurisdicciones que le son contestadas por los mismos que están sometidos a ellas y por los organismos a través de los cuales está establecido que se ejerzan dichas competencias. Los límites no se hallan definidos y, entre el mercadeo y los recursos y contrarrecursos, se sitúa la difícil posición de la monarquía. El conflicto, tal como venimos afirmando, surge cuando el monarca, según las circunstancias y sus propias necesidades, se sitúa al lado de unos y otros, creando las condiciones de la duplicidad de competencias. $Y$, dado que su palabra es la ley, produciendo confusión y en muchos casos las bases de largos pleitos.

\section{LOS MUNICIPIOS}

Desde inicios de la Edad Media, donde los señoríos no constituían una unidad territorial, tenía lugar la aparición de consejos y universidades que asumían las funciones administrativa y judicial e incluso la legislativa, pues eran los señores los que concedian los fueros y privilegios ${ }^{29}$. Esta afirmación del profesor Lalinde nos parece fundamental ya que nos orienta a reforzar nuestra idea de la actuación real como subsidiaria donde no existía una administración feudal. En este municipio incipiente, vemos como tienen lugar los fenómenos de: creciente concentración de riquezas, simplificación de estructuras internas y también la aparición de la nueva "élite de parroquia» ${ }^{30}$, compuesta por la baja nobleza y por los payeses prósperos. EI síndic de la parroquia, que en un principio era un representante nombrado

29 Lalinde Abadia, J. Derecho histórico..., p. 242.

30 Amelang, J. "Les estructures socials de l'Europa Renaixentista". L'Avenc, n. ${ }^{\circ} 65$, noviembre 1983, p. 49 
por el consejo para encargos concretos (similar a los obrers de la parroquia ${ }^{31}$ ), terminará por convertirse en un cargo definitivo para el inicio del funcionamiento del gobierno municipal. Pero no siempre la fundación del municipio y su gobierno autónomo supone el final del derecho feudal ${ }^{32}$.

En el siglo xv, la evolución de la institución municipal, trae como consecuencia la aspiración de los habitantes del término a gozar de privilegios que les liberen de las antiguas cargas feudales y les equiparen a los pobladores de la capital del Principado. Son múltiples en este periodo las concesiones de privilegios reales a tal respecto. Un ejemplo de ellas es la concesión del llamado dret de carreratge, mediante este privilegio la población es nombrada carrer de Barcelona, con lo que (teóricamente) pasa a depender de la jurisdicción de la capital. El dret de carreratge se concede en 1424 para Mataró y en 1480 para Argentona, Cabrera, Vilassar y Premià. Por este procedimiento y tras el pago por el dret de veinatge, el Consejo de Barcelona recibia el sacramento y homenaje de los síndicos del municipio y el mer imperi quedaba en manos de Barcelona, mientras que la justicia civil y criminal seguía administrada por los batlles locales de nombramiento real. A su vez el Consejo de Barcelona se comprometía a defender vidas, hacienda, usos, prerrogativas y gracias; y los pueblos respectivos quedaban obligados a contribuir a las obras de interés general y a comparecer para agregarse a la bandera de Barcelona en el somatent ${ }^{33}$. Vemos como todo sigue bajo el parámetro feudal, un parámetro demasiado "encorsetado» para promover libertades.

Recordemos que el pleito que estudiamos se entabla por la propiedad de las jurisdicciones entre los síndicos de las universidades y el señor feudal, y que existen muchos pleitos como éste en la Real Audiencia a finales de la Edad Media y durante toda la Edad Moderna. Así mismo, en toda la documentación, vemos el interés de los síndicos por demostrar ante la Real Audiencia que no son válidas las pretensiones de jurisdicción del noble. En realidad no están en contra del pago de los censos en general y de las cargas feudales, su intención es que el control de la fiscalidad pase al Consejo de la Universidad, y sea administrada por el batlle real.

En este sentido, la pragmática dada por el rey Felipe en 1553, y que es presentada en pleito, recoge las verdaderas aspiraciones de los síndicos.

31 PONS i GURI, J.M. «Ordinacions...», p. 62.

32 Pons i Gurl, J.M. Dels privilegis al régim municipal de Calella. Calella, Ajuntament de Caiella, 1988, pp. 62-64.

32 Broca de Montagut, G. Historia del derecho de Cataluña, especialmente el civil. Barcelona, Generalitat de Catalunya. Departament de Justícia, 1985, pp. 337-340. 
Batlles reales y batlles de sachs. Contribución al estudio de las jurisdicciones...

Recuerda la incorporación de las poblaciones a la jurisdicción de la ciudad de Barcelona y afirma que a quién corresponde su ejecución es a los batlles reales de cada población, elegidos por trienios entre los naturales de las mismas, concretando incluso cuál deberá ser la remuneración de los batlles de Mataró y de los otros municipios. También solicitan los síndicos que las penyoras hechas en Mataró se queden en la misma ciudad, para facilitar su devolución, aun en el caso de intervenir el batlle de Barcelona, asi el proceso es controlado por ellos, sobre todo por si se llega a la subasta de los bienes incautados.

En resumen, el proceso en general nos demuestra que los síndicos, o la parte litigante contra el noble, luchan básicamente por la liberación o independencia respecto del poder jurisdiccional y fiscal del señor. Dicha liberación supondrá un traspaso de competencias jurídicas y fiscales, que debe hacerse del batlle noble al batlle real, administrador del patrimonio regio en los nacientes municipios, y que finalmente les proporcionará a ellos, como representantes de estos municipios, el poder que pierda el noble.

\section{RESISTENCIA CAMPESINA}

Es evidente que el campesino no dispone de una situación legal clarificada, por la confusión entre la remensa, las cargas serviles y los derechos señoriales, y tampoco de una conciencia real de su significado; lo que no impide que durante toda la Edad Media y la Moderna, tenga lugar una destacada resistencia del campesinado a pagar los censos y otros derechos dominicales. Esta resistencia frente al noble o al oficial que intenta cobrar las rentas feudales, adopta multitud de formas ${ }^{34}$, y es posible gracias a varios factores, como el conjunto de usos y prácticas de carácter comunitario derivados de la misma actividad productiva, el hecho de estar sometidos a los mismos derechos y abusos feudales, y principalmente a la existencia de una auténtica cohesión de grupo.

Por lo que se refiere a la documentación que analizamos, hemos podido constatar que a pesar de que los libros de los batlles de sachs son presentados como prueba del poder ejecutivo del señor feudal, en sus actas aparecen ejecuciones en las que se refleja la actuación de los oficiales (reales y señoriales) como consecuencia de dicha resistencia campesina. Así aparece textualmente: "be sempre que los seus emphiteutes y

34 Serra, E. Pagesos i senyors..., pp. 49-56. 
homes propis han reusat de pagar los censos y altres". En estas actas encontramos resistencia pasiva y activa por parte del campesinado, y actuaciones duras por parte de los oficiales del noble llegando al inventariado y la subasta de los bienes de los deudores y a la violencia física, como en el caso que relatan los síndicos de la mujer de Joan Andreu, tejedor de lino: "sa muller que per no voler aquella donar penyora la maltrataven".

Delante de la resistencia o negativa a pagar los censos, el procedimiento utilizado es parecido en todos los casos: Una vez anunciada la deuda, se toma un objeto en prenda y se dan 10 días para proceder al pago. Pasados dichos días, se persona en casa del deudor el batlle de sachs junto con sus oficiales, un notario y un portero real, que, tal como consta en el acta, asiste al batlle de sachs. Entonces se procede a inventariar sus bienes y se comunica un nuevo plazo al interesado. Si el importe tampoco es abonado en este término, los bienes inventariados son vendidos en pública subasta, en la plaza del lugar. Aunque, para tener una visión completa de los hechos, habría que confirmar si todas las subastas anunciadas en los libros de cort se llevaron a cabo y qué consecuencias tuvieron para los habitantes de la propiedad incautada.

En todo caso, la resistencia campesina, tal como consta en la documentación estudiada, no iba dirigida concretamente contra las cargas feudales, sino contra la duplicidad de la jurisdicción y la fiscalidad, consecuencia de las actuaciones de los oficiales reales por una parte y de los oficiales señoriales por otra. Por ejemplo, en el acta del proceso contra Antoni Atmetller la respuesta que da él como deudor es que ya sabe los censos que debe pagar, pero a partir de aquí, el noble deberá demostrar si está obligado a pagarle otros, o la respuesta de Àngela Genera que dice no conocer a los oficiales del señor y repite varias veces que ja ha pagado los censos.

Por tanto deberíamos replantearnos de nuevo, en primer lugar los objetivos de esta resistencia campesina y también hasta qué punto será la base, tal como se ha afirmado repetidas veces, de las revoluciones que tienen lugar en el paso de la Edad Media a la Edad Moderna.

\section{CONCLUSIONES}

Dentro del estudio de las instituciones y su evolución, hemos de destacar como importante fuente documental los pleitos mantenidos entre los síndicos de las universidades y los señores locales. El hecho de que estos pliegos recojan las pruebas documentales presentadas por ambas partes garantiza 
la selección de los aspectos que para ellas eran básicos en el proceso. En el presente caso, el pleito es por la posesión de la jurisdicción por parte del señor del término, interesante aspecto que nos da muchas pistas para comprender el funcionamiento jurídico y fiscal del señorío, y a su vez la oposición de los síndicos nos muestra cuáles eran sus aspiraciones.

Una vez analizada la documentación del pleito entre don Miquel Desbosc i los síndicos de las universidades, hemos constatado que a finales de la Edad Media en la baronía Desbosc, cuyas bases económicas se sustentan en la legalidad feudal, su propietario intentaba seguir manteniendo su rentabilidad. En contra, las nacientes universidades de Vilassar y Argentona, dirigidas por una nueva élite de ciudadanos pleitean con insistencia contra estos antiguos derechos feudales. En la causa estudiada, el argumento a favor y en contra gira en torno del oficial del señor, el batlle de sachs, y de sus competencias, así como del interesante aspecto de la asistencia del batlle real en los procesos ejecutivos, que los síndicos niegan rotundamente y el señor se esfuerza en demostrar.

Sin embargo, el análisis de la documentación nos demuestra cómo los oficiales reales y señoriales actúan indistinta y conjuntamente, constando sus actos en el mismo libro de corte. Los mecanismos fiscales y ejecutivos feudales siguen funcionando, mientras se hace patente un creciente fenómeno de lucha por el control de la jurisdicción tanto por parte del barón como de los síndicos. Estos síndicos que, como representantes de la universidad, parece que deberían haber aportado un intento de liberalización de la estructura social local, en realidad usan, defienden y se apoyan en los mismos mecanismos feudales para controlar el poder local. A su vez la monarquía, fuente teórica de legalidad, por medio de prerrogativas y de la actuación de sus propios agentes, da origen a la confusión y a las bases en las que se apoyan las distintas partes en los pleitos. En realidad, la política pactista, las presiones oligárquicas y las necesidades monetarias son las causas principales de la actuación del rey en Cataluña.

La principal conclusión a la que hemos podido llegar es el mantenimiento de las estructuras legales y fiscales del feudalismo en los inicios de la Edad Moderna. Este sistema feudal no desaparece a causa de las sucesivas revueltas, ni por las disposiciones reales. Sencillamente se extingue, pero se trata de una extinción lenta, y, tal como podremos comprobar en futuros trabajos, los elementos feudales pervivirán a lo largo de toda la Edad Moderna. 